\title{
Mineração do ouro no período colonial: alterações paisagísticas antrópicas na serra de Ouro Preto, Minas Gerais
}

\section{Gold mining in the colonial period: landscape anthropic changes at serra de Ouro Preto, Minas Gerais}

Frederico Sobreira

Universidade Federal de Ouro Preto

frederico.sobreira@pq.cnpq.br

\begin{abstract}
RESUMO
A descoberta do ouro nas cabeceiras da bacia do ribeirão do Carmo em fins do século XVII provocou um processo migratório na província de Minas Gerais e o surgimento de vários povoados, que originaram posteriormente as vilas que hoje são as cidades de Ouro Preto e Mariana. As atividades de mineração ocorreram tanto no leito dos cursos de água como nas vertentes da serra de Ouro Preto e no interior dos maciços, neste caso por trabalhos subterrâneos. Entre os processos utilizados, o desmonte manual ou hidráulico dos depósitos de vertentes e do substrato mais friável foi o procedimento que deixou os vestígios mais marcantes das atividades mineiras, representados por grandes áreas escavadas e totalmente modificadas em relação à sua morfologia e estabilidade originais. Os principais sítios destas atividades, pela extensão e volume de material mobilizado, estão nas vertentes da serra nos atuais limites a norte da área urbana de Ouro Preto, já parcialmente ocupada pela malha urbana, e nas encostas e topos a montante da área urbana do distrito de Passagem de Mariana (Mariana), cobrindo uma área total de cerca de 300 hectares. Estas áreas foram delimitadas e caracterizadas como áreas de erosão tecnogênica, sendo possível em alguns locais a reconstituição da paisagem original a partir de testemunhos topográficos e a estimativa do volume de material retirado. Porém, os depósitos correlatos a estes processos erosivos foram destruídos pela dragagem do ribeirão na década de 1980 por companhia de mineração. Esta paisagem modificada tem importância histórica e cultural para as cidades e a região, e deve ser integrada ao seu patrimônio geomineiro como testemunho da capacidade de alteração do meio físico pela ação antrópica, mesmo com técnicas primitivas.
\end{abstract}

Palavras-chave: Erosão tecnogênica; Mineração no século XVIII; Ouro Preto.

\begin{abstract}
The discovery of gold in the headwaters of the Carmo Creek basin at the end of the seventeenth century caused a migration process in the province of Minas Gerais and the emergence of several villages, which subsequently originated the villages that are now the cities of Ouro Preto and Mariana. Mining activities occurred both in the bed of watercourses as in the slopes of the Serra de Ouro Preto and inside the mountains, in this case through underground work. Among the processes used, the manual or hydraulic dismantling of deposits found in slopes and in friable substrates was the procedure that left the most significant traces of mining activities, represented by large excavated areas, fully modified with respect to their original morphology and stability. The main sites of these activities for the extent and volume of mobilized material, are the slopes of Serra de Ouro Preto on the current boundaries to the north of the urban area of Ouro Preto, already partially occupied by the urban network, and the slopes and tops upstream of the urban area of the district of Passagem de Mariana (Mariana), covering about 300 hectares. These areas were delimited and characterized as sites of technogenic erosion, being possible in some places the reconstitution of the original landscape from topographic testimonies and the estimated volume of removed material, but the deposits related to these erosive processes were destroyed by the dredging of the creek in the 1980s. This changed landscape has historical and cultural importance to the city and the region and must be integrated to their geological and mining heritage as testimony of the human ability to change the physical environment, even using primitive techniques.
\end{abstract}

Keywords: Technogenic erosion; Mining in the eighteenth century; Ouro Preto.

\section{Introdução}

A descoberta do ouro em Minas Gerais nos primórdios do século XVII ativou a vida socioeconômica do Brasil e, principalmente, da
Província Minas Gerais, gerando um novo centro de produção e consumo. Durante mais de um século foram desenvolvidas atividades extrativas na região onde hoje estão implantadas as cidades de Ouro Preto e Mariana, com o desenvolvimento tanto nos vales e aluviões, 
como nas vertentes da serra de Ouro Preto, feição fisiográfica marcante na região.

A mineração iniciou-se pelos depósitos aluvionares, onde eram empregadas técnicas relativamente simples. Com o passar do tempo, a conjugação de experiências de brasileiros, portugueses e africanos tornou a explotação mais elaborada (Ferrand 1894). Nos serviços em leitos de rios eram implantados sistemas de desvio dos cursos d'água por barragens e também eram explorados depósitos nas margens dos rios, chamados de taboleiros.

Porém, as atividades que mais deixaram na região concentraram-se nos veios auríferos nos maciços rochosos e, de maneira mais notável, nos depósitos que ocorriam nos flancos das montanhas (grupiaras) e nas rochas mais alteradas e friáveis do substrato rochoso (Lima \& Miranda 1996). Nos veios auríferos era necessária a abertura de minas para exploração subterrânea, enquanto nas vertentes empregava-se o desmonte manual ou hidráulico, gerando uma lama que era acumulada em reservatórios (mundéos) para depois ser trabalhada.

A dimensão destes trabalhos e as formas resultantes na paisagem são exemplos marcantes da ação antrópica no meio físico e do trabalho do homem como agente geológico, caracterizando um processo erosivo tecnogênico. No entanto, os reflexos destas atividades atingiram não só os locais de extração do material, mas todo o curso do ribeirão do Carmo a jusante de Ouro Preto e Mariana, que recebeu um volume inestimável de sedimentos gerados pelas atividades extrativas nas suas cabeceiras.

Os locais onde houve mais modificações na paisagem da serra de Ouro Preto foram as vertentes nos limites a norte da atual área urbana de Ouro Preto e a região a montante da área urbana do distrito de Passagem de Mariana (Mariana). Estas áreas foram mapeadas e caracterizadas, sendo possível em alguns locais a reconstituição da paisagem original a partir de testemunhos topográficos e a estimativa do volume de material retirado pelos trabalhos de mineração. Este registro é importante, uma vez que nas últimas décadas vem ocorrendo um processo de ocupação desordenada dessas antigas áreas de mineração, que tende a gerar situações de riscos geológicos, além de obliterar ou destruir os vestígios arqueológicos das atividades mineiras.

\section{Aspectos históricos}

Durante os primeiros séculos do período colonial brasileiro, a província de Minas Gerais permaneceu inexplorada em relação às outras províncias brasileiras, devido principalmente ao seu relevo acidentado, à densa vegetação e até aos índios antropófagos (Eschwege 1833) constituindo uma barreira muitas vezes intransponível. Somente no final do século XVII o ouro foi descoberto e começou a ser extraído em Minas Gerais, particularmente na região onde se encontram as áreas urbanas atuais das cidades de Ouro Preto e Mariana e o distrito de Passagem de Mariana, localizado entre elas. O descobrimento do ouro ativou a vida socioeconômica do Brasil, e principalmente das Minas Gerais, gerando um novo centro de produção e consumo, uma vez que a economia açucareira ia de mal a pior. A abundância com que se retirava o ouro causou uma imigração em direção ao interior do país.

Durante a primeira metade do século XVIII, o desenvolvimento da Província e a riqueza gerada para a Coroa tornaram sua capital Vila Rica (atual Ouro Preto) um dos maiores centros populacionais do interior do território. Segundo Ferrand (1894), em 1750 existiam cerca de 80 mil trabalhadores livres ou escravos extraindo ouro na região. É interessante notar que na década de 80 do século $X X$, as atividades de garimpo em Serra Pelada possuíam a mesma quantidade de trabalhadores. Considerando-se as dificuldades de acesso e comunicação do período colonial, o número impressiona.

O período em torno dos meados do século XVIII pode ser considerado como o apogeu da extração do ouro na região. Porém, a partir da metade daquele século a mineração começou a decair.

Discutem-se muito as causas principais da decadência do chamado "Ciclo do Ouro" em Minas Gerais. O imposto do quinto (quinta parte de todo o ouro apresentado era recolhido) sem dúvida foi uma delas, aliado a um aspecto técnico bastante importante, pois com o passar do tempo as reservas aluvionares superficiais foram se esgotando. Os mineradores contavam com métodos rudimentares de extração e não estavam preparados para minerar depósitos menos óbvios e de mais difícil extração. Assim, a insensibilidade por parte da Corte em não planejar em longo prazo as atividades de mineração do ouro na capitania e a rigidez da política tributária levaram as minas a um estado de quase inércia. Posteriormente, a exaustão das melhores jazidas tornou a atividade pouco lucrativa, decretando o fim do ciclo de extração do ouro, já no início de século XIX.

\section{Caracterização do meio físico}

Ouro Preto e Mariana localizam-se na região central do Estado de Minas Gerais, distando cerca de 100 km da capital, Belo Horizonte. As cidades estão situadas na extremidade sudeste da região conhecida como Quadrilátero Ferrífero, na zona mínero-metalúrgica de Minas Gerais e encontram-se nas cabeceiras do rio Doce, na sub-bacia do Ribeirão do Carmo (figura 1).

Segundo Sobreira \& Fonseca (2001), o principal elemento da paisagem na área urbana é a Serra de Ouro Preto, divisor de duas grandes bacias de drenagens regionais, dos Rios das Velhas e Doce. As altitudes estão entre $1.500 \mathrm{~m}$ nas partes altas de Ouro Preto e $750 \mathrm{~m}$ nas partes mais baixas da cidade de Mariana. A morfologia local caracteriza-se por altas montanhas de desenvolvimento linear, áreas aplainadas com altitudes diversas e vales alongados, muitas vezes bem encaixados. Os traços do relevo, acidentado com vertentes bem íngremes e vales profundos e 
encaixados, são nitidamente condicionados pelo substrato geológico.

No contexto geológico regional, as cidades localizam-se em uma grande estrutura conhecida como Anticlinal de Mariana. Ouro Preto e Passagem de Mariana estão implantadas no flanco sul dessa estrutura, nas vertentes da serra de Ouro Preto, enquanto Mariana ocupa a terminação periclinal e o flanco norte do anticlinal (serra de Antônio Pereira), em um vale mais amplo e na planície aluvionar do mesmo rio (Sobreira \& Fonseca 2001).

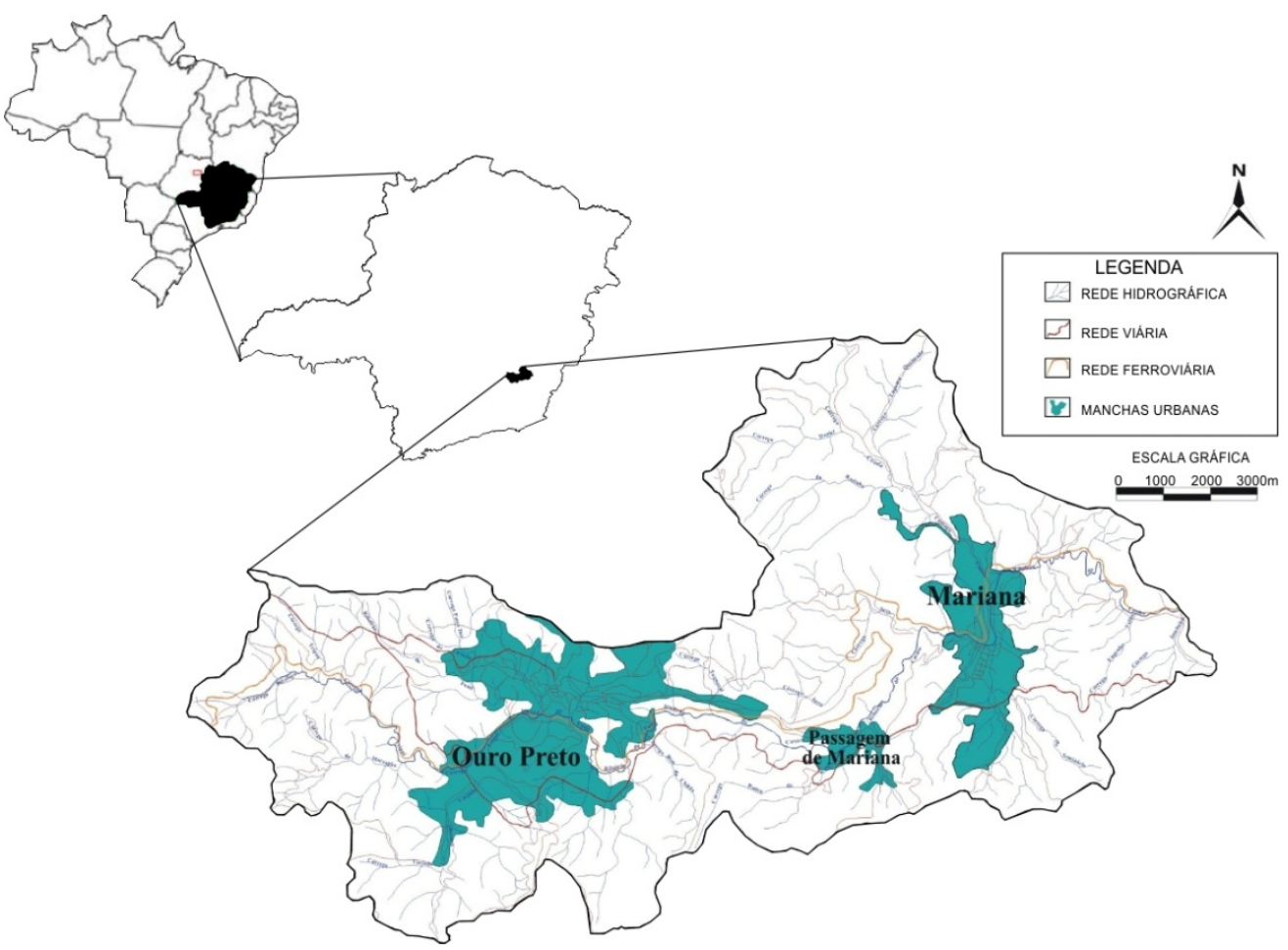

Figura 1: Localização das cidades de Ouro Preto e Mariana

Na serra de Ouro Preto, o substrato rochoso é constituído por metassedimentos de idade paleoproterozoica - filitos, quartzitos, xistos e formações ferríferas - profundamente afetados por eventos tectônicos. Apesar de bem deformadas, as formações geológicas orientam-se de um modo geral na direção leste-oeste, com mergulhos para sul, na ordem dos $30^{\circ}$ (Sobreira \& Fonseca 2001).

As unidades geológicas ocorrentes pertencem aos grupos Nova Lima, composto por quartzo-sericitaxistos alterados; Caraça, representado por quartzitos sericíticos da Formação Moeda e filitos carbonosos pertencentes à Formação Batatal; e Itabira composto por formações ferríferas bandadas (Door II 1969). Estas unidades estão distribuídas na forma de camadas contínuas, com variações verticais ou laterais, podendo desaparecer em alguns pontos. No contato entre as duas primeiras unidades ocorrem as principais zonas mineralizadas, embora o ouro apareça também em veios nas formações ferríferas e quartzíticas (Vial et al. 2007).

É comum a ocorrência, nos topos e nas vertentes dos morros, de coberturas superficiais de crosta laterítica, localmente denominadas de "canga”. Estes materiais, de idade terciário-quaternária, são produtos de alteração supergênica em climas tropicais. Os solos, quando ocorrem, são muito pouco espessos, na ordem dos centímetros, exceto por algumas manchas maiores de material coluvionar.

As litologias caracterizam-se por apresentar, além da foliação metamórfica marcante, descontinuidades planares (falhas e fraturas), que influenciam profundamente seu comportamento geotécnico, que tem também a contribuição do estado de alteração e o intenso fraturamento das rochas locais (Sobreira \& Fonseca 2001). A figura 2 mostra o recorte da geologia da serra de Ouro Preto e o perfil geológico com as principais unidades. 


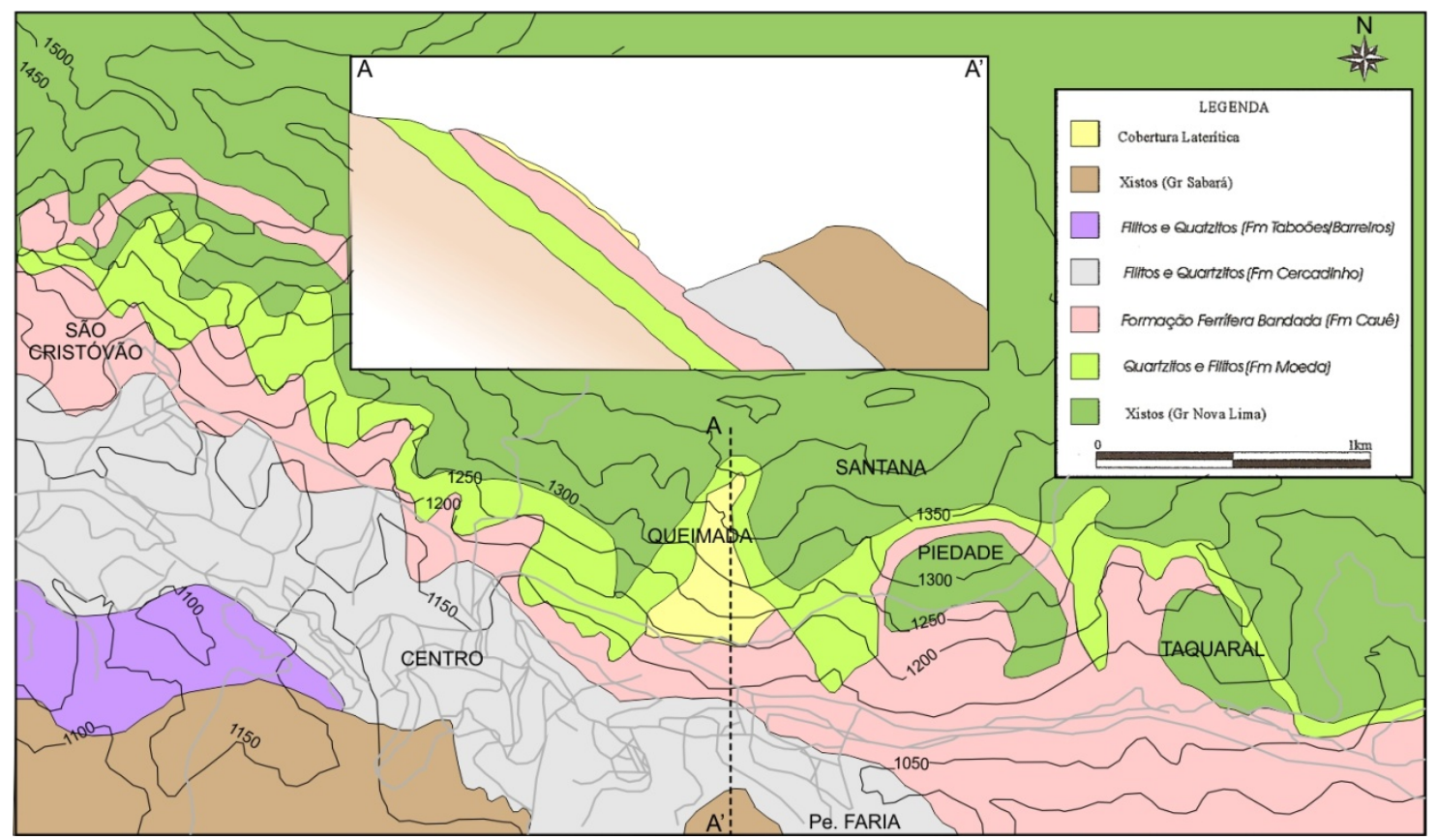

Figura 2: Geologia de parte da serra de Ouro Preto e perfil geológico representativo (adaptado de Sobreira \& Fonseca 2001)

As mineralizações de ouro estão associadas a sulfetos (arsenopirita, pirita e calcopirita) e turmalinitos, distribuídos de forma restrita e irregular, nos fraturamentos e zonas de cisalhamento e nos contatos entre as unidades litológicas. As principais zonas mineralizadas ocorrem no contato dos xistos do Grupo Nova Lima com o quartzito da Formação Moeda, na forma de veios que cortam os quartzitos da Formação Moeda e no contato do quartzito Moeda com o filito Batatal (Cavalcanti 1999).

\section{Mineração do ouro}

Embora o ciclo do ouro no período colonial tenha sido muito relatado em seus aspectos econômicos, políticos e sociais, são poucos os trabalhos que versam sobre as atividades extrativas do ouro especificamente e todos estes relatos foram bem posteriores ao apogeu da mineração no século XVIII. Eschwege (1833) foi quem primeiro se preocupou com a questão, posteriormente abordada por Ferrand (1894) e Calógeras (1904) e, mais tarde, por Lacourt (1937). Somente na década de 1990 a temática voltou a ser abordada por pesquisadores contemporâneos.

Segundo Eschwege (1833), nos primeiros tempos de exploração, os trabalhos foram limitados aos depósitos aluvionares, que o autor classificou em três tipos: os veios, que consistiam no leito dos rios, os taboleiros, depósitos nas margens dos rios em um nível logo acima do leito, e as grupiaras, depósitos mais elevados situados no sopé das montanhas. Estes depósitos (principalmente os dois primeiros) foram, em princípio, o alvo principal dos mineradores, que atraídos por sua riqueza aurífera e facilidade de extração, tomaram de assalto o leito dos rios da região.

O que se buscava era o cascalho aurífero, revolvendo os leitos dos rios em várias posições. Para otimizar a produção, os métodos foram aos poucos se aperfeiçoando. Os mineradores passaram então a adotar um sistema que consistia em desviar a água de seu curso principal, construindo pequenas barragens que buscavam facilitar a extração do ouro ali concentrado.

Nas grupiaras, cuja posição era mais elevada nas encostas, recorria-se a métodos extrativos diferentes, em estruturas chamadas canoas. Neste processo, as águas eram captadas em áreas mais elevadas e conduzidas por canais até os locais dos trabalhos. O material desmontado se acumulava em longos degraus escalonados a jusante, deixando passar a água turva e permitindo que o material mais pesado, de maior interesse, ficasse retido.

Com a intensidade dos trabalhos e esgotamento das melhores jazidas, os mineradores começaram a desenvolver atividades nos depósitos mais elevados e nas rochas nos flancos das montanhas adjacentes, ou por escavações subterrâneas ou por desmontes e retrabalhamento do material mobilizado. Eschwege (1833) classificou os depósitos em três categorias, de acordo com o local em que a jazida se encontrava: nos vales, no flanco e no seio das montanhas. Neste último tipo, a extração se dava por minas subterrâneas, ainda hoje espalhadas em parte da área urbana e entorno de Ouro Preto e Passagem de Mariana. Quando a ocorrência da jazida se dava em um vale, o método empregado não tinha nada de sofisticado. Apenas escavava-se a rocha a fim de atingir a camada mais rica e retirar alguma quantidade de material, que era transportada pelos escravos para posterior apuração.

Já, nos flancos das montanhas, as atividades buscavam a extração do ouro que ocorria disseminado ou em níveis estratiformes na formação ferrífera bandada nos setores em que estes terrenos encontravam-se mais alterados e friáveis, portanto de 
mais fácil desmonte. Este tipo de extração provocou a maior intervenção antrópica ao meio físico realizada na região, que modificou significativamente a geomorfologia da serra de Ouro Preto. Como a principal ferramenta utilizada era novamente a água, houve grande desenvolvimento na tecnologia dos aquedutos e reservatórios posicionados nas partes mais altas, com o objetivo de intensificar a força da água. As lamas geradas pelo desmonte hidráulico eram carregadas pelas águas e armazenadas em reservatórios chamados mundéos, para depois serem apuradas pelos processos de separação convencionais (rampas e bateamento). Geralmente, os mundéos eram de alvenaria escalonados nos talvegues, sendo conectados por canais comunicantes para aumentar a capacidade de armazenamento do conjunto.

Assim, nos locais das lavras de ouro foram realizados grandes desmontes, escavações, transporte e deposição de material removido, abertura de poços, galerias e canais, além de desmatamento generalizado. Os sinais desta ação são claramente perceptíveis até hoje, principalmente na serra de Ouro Preto, quase que totalmente afetada pela atividade mineradora.

\section{Ação antrópica no meio físico}

Se na lavra subterrânea, mais localizada, não houve critérios no planejamento e desenvolvimento das atividades, muito pior aconteceu nos trabalhos a céu aberto, que envolveram extensas áreas e cujo passivo ambiental deixado foi muito maior, uma vez que as alterações na morfologia da serra foram intensas, com grandes desmontes e acúmulo de material estéril em pilhas, caracterizando um processo quase que totalmente aleatório e predatório, descompromissado com o futuro uso destas áreas.

O desmonte hidráulico era o processo mais comum, aproveitando águas de chuvas ou captadas de nascentes na serra de Ouro Preto. Estes trabalhos de mineração representaram a primeira grande intervenção antrópica no meio físico na serra de Ouro Preto, resultando na descaracterização do ambiente natural. Para se chegar à zona mineralizada na formação ferrífera, era necessário proceder à destruição da crosta laterítica (canga), cujos blocos e fragmentos resultantes eram jogados encosta abaixo, ou por vezes acumulados em pilhas, que em alguns pontos atingiram dimensões consideráveis, com alturas entre 20 e 30 metros (Sobreira \& Fonseca 2001). Por vezes as formações sobrepostas à zona mineralizada eram totalmente removidas, deixando o quartzito da Formação Moeda exposto.

A atividade simultânea de milhares de escravos, durante um período de quase cem anos, provocou uma alteração paisagística e ambiental de grandes proporções, com a total mudança da geometria das encostas, alteração da rede de drenagem natural, formação de grandes depósitos de detritos e blocos rochosos à meia encosta, criação de taludes íngremes e instáveis e desencadeamento de processos erosivos acelerados, que passaram a atuar como principal condicionante ao desenvolvimento e evolução das encostas. Os terrenos não atingidos pelos desmontes, com cobertura de crosta laterítica mais resistente, representam testemunhos do ambiente natural anterior à ação antrópica.

Uma vez cessadas as atividades de mineração, os processos erosivos e de movimentação de massa passaram a comandar a geodinâmica superficial da serra, fazendo com que muitas áreas, com o passar do tempo, atingissem um estado de equilíbrio, na maioria das vezes precário.

Embora as atividades de desmonte se estendessem por cerca de $10 \mathrm{~km}$ ao longo das vertentes da serra de Ouro Preto, duas grandes áreas se destacam pela extensão e volume de material mobilizado: as vertentes da serra nos limites a norte da atual área urbana de Ouro Preto, já parcialmente ocupada pela malha urbana, e as encostas e topos a montante da área urbana do distrito de Passagem de Mariana (Mariana), em área ainda conservada (figura 3). Como o contexto geológico e os processos de extração por desmonte eram os mesmos para toda a serra de Ouro Preto, o quadro atual de um local para outro não é muito diverso, exceto pela maior ou menor intensidade das atividades ou pela existência de ocupação urbana recente, geralmente caracterizando situações de risco geológico. Nos limites de Ouro Preto, a maior parte da superfície da serra, do terço inferior das vertentes até o topo, foi escavada em diversas intensidades. Os desmontes alcançaram uma extensão de cerca de 300 ha. Sobreira \& Fonseca (2001) realizaram levantamento de toda a serra de Ouro Preto na área urbana da cidade, concluindo que cerca de $70 \%$ das encostas foram alteradas pela ação de extração do ouro no século XVIII. As alterações foram de tal monta, que qualquer observador mais atento pode hoje verificar não se tratar de uma paisagem natural a vertente da Serra de Ouro Preto que delimita a cidade a norte.

Embora a área de mineração a céu aberto seja praticamente contínua, alguns locais ficaram mais conhecidos como núcleos das atividades de desmonte, quase todos parcialmente ocupados por casas, vias e ruas, sendo os principais deles conhecidos hoje como bairros São Cristóvão (Veloso), Volta do Córrego, Lages, Santana, Piedade e Taquaral, nomes herdados das antigas minas.

As figuras 4 e 5 detalham as alterações feitas nos bairros São Cristóvão e Volta do Córrego e os testemunhos do relevo original. Esses bairros localizam-se no setor oeste da área urbana de Ouro Preto.

No bairro Lajes, a montante do centro histórico, a remoção das formações superiores deixou o quartzito sotoposto exposto e apenas alguns testemunhos do relevo original (figura 6), enquanto no entorno do local conhecido como Morro da Queimada veem-se claramente as escarpas e vales formados pelas escavações, ficando os terrenos mais resistentes como testemunhos do relevo anterior (figura 7). 


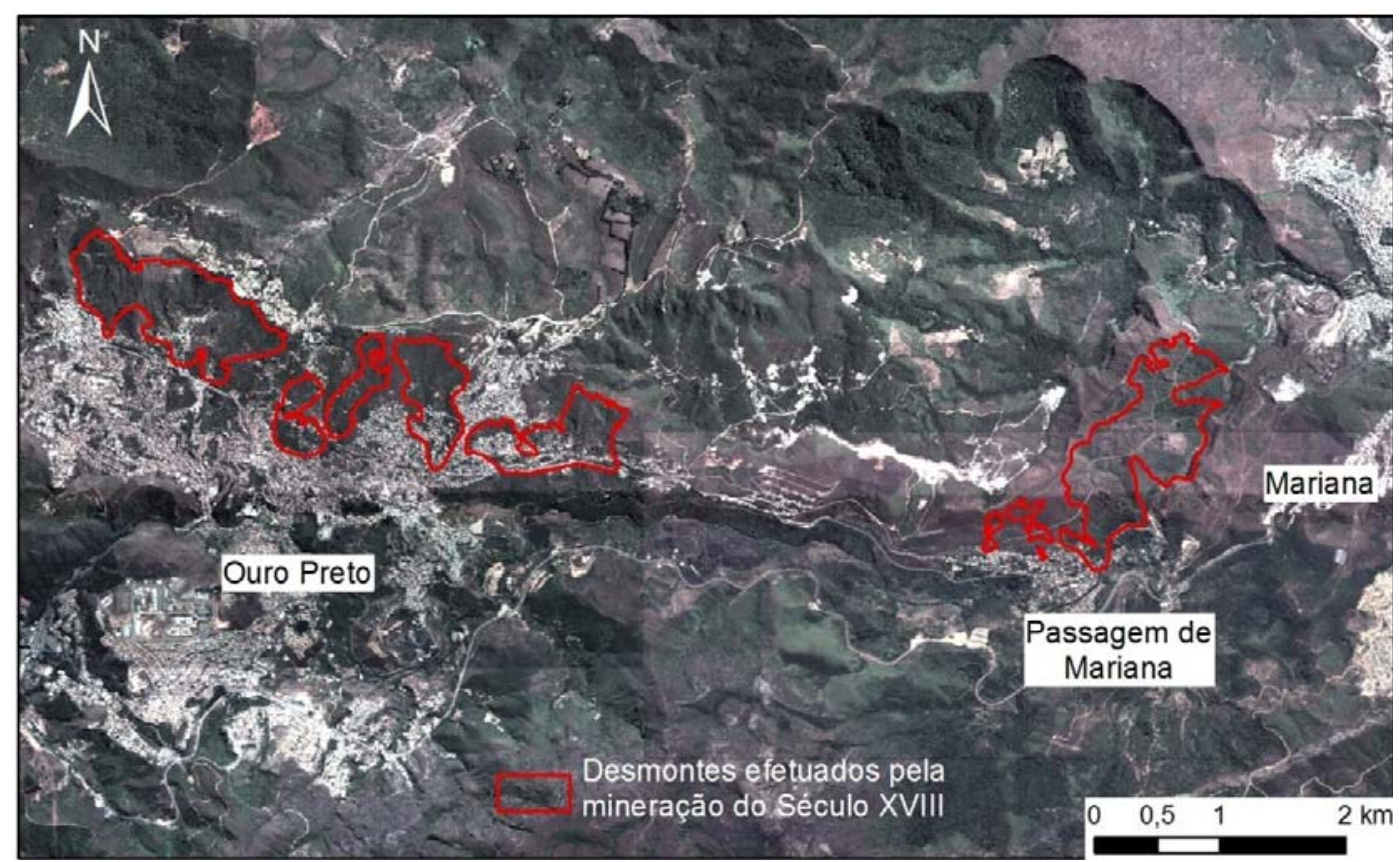

Figura 3: Imagem das áreas urbanas de Ouro Preto e Mariana e das áreas escavadas pelas atividades de mineração do século XVIII

Já, na porção leste da área urbana de Ouro Preto, os bairros Piedade, Santana e Taquaral estão quase totalmente instalados em antigas áreas de mineração e seu entorno (figura 8). Neste último local, além das feições remanescentes dos desmontes verifica-se a ocorrência de depósitos de material estéril (canga), que formam pilhas de até 30 metros de altura, com cerca de 3 ha de extensão, infelizmente todas mascaradas pela ocupação urbana.

Todas estas áreas alteradas pelas atividades mineiras têm problemas quanto à estabilidade dos terrenos por vários motivos, como os declives acentuados, as

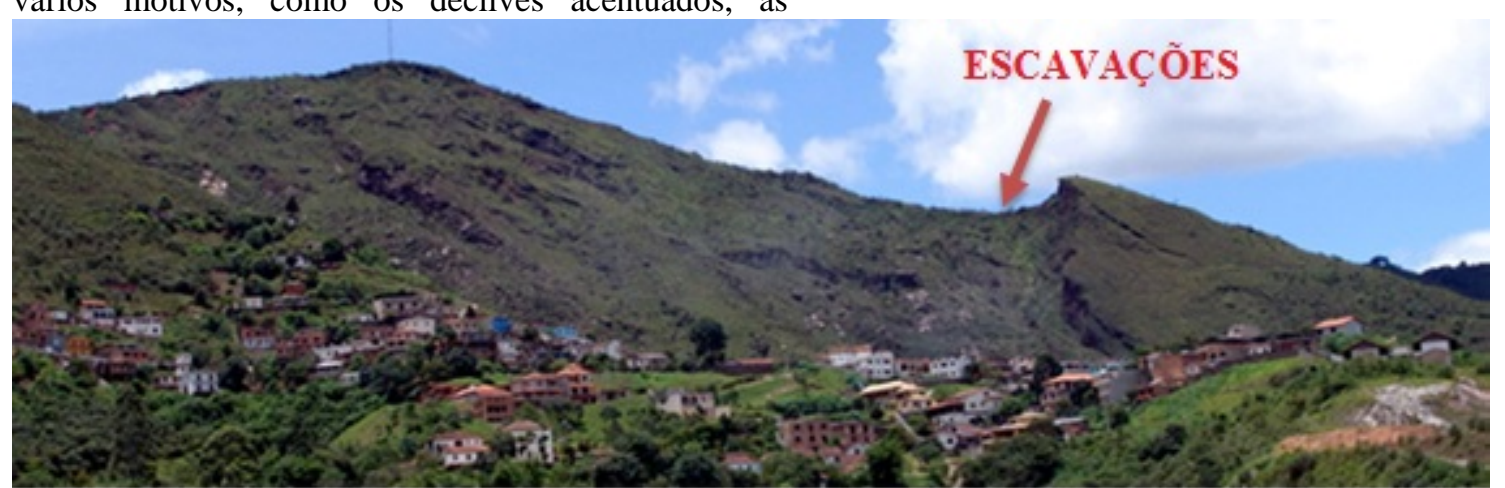

Figura 4: Alterações na morfologia das vertentes pelos desmontes da mineração do século XVIII no bairro São Cristóvão, Ouro Preto péssimas qualidades geotécnicas dos depósitos produzidos, a existência de inúmeros blocos rochosos e de crosta laterítica dispersos pelas encostas, a drenagem irregular e a inexistência de cobertura vegetal de porte (Sobreira 1991). A grande heterogeneidade dos depósitos de superfície resultantes das atividades de mineração torna muito difícil, senão impossível, caracterizá-los geotecnicamente, mas estes terrenos nunca possuem boas condições de estabilidade. 


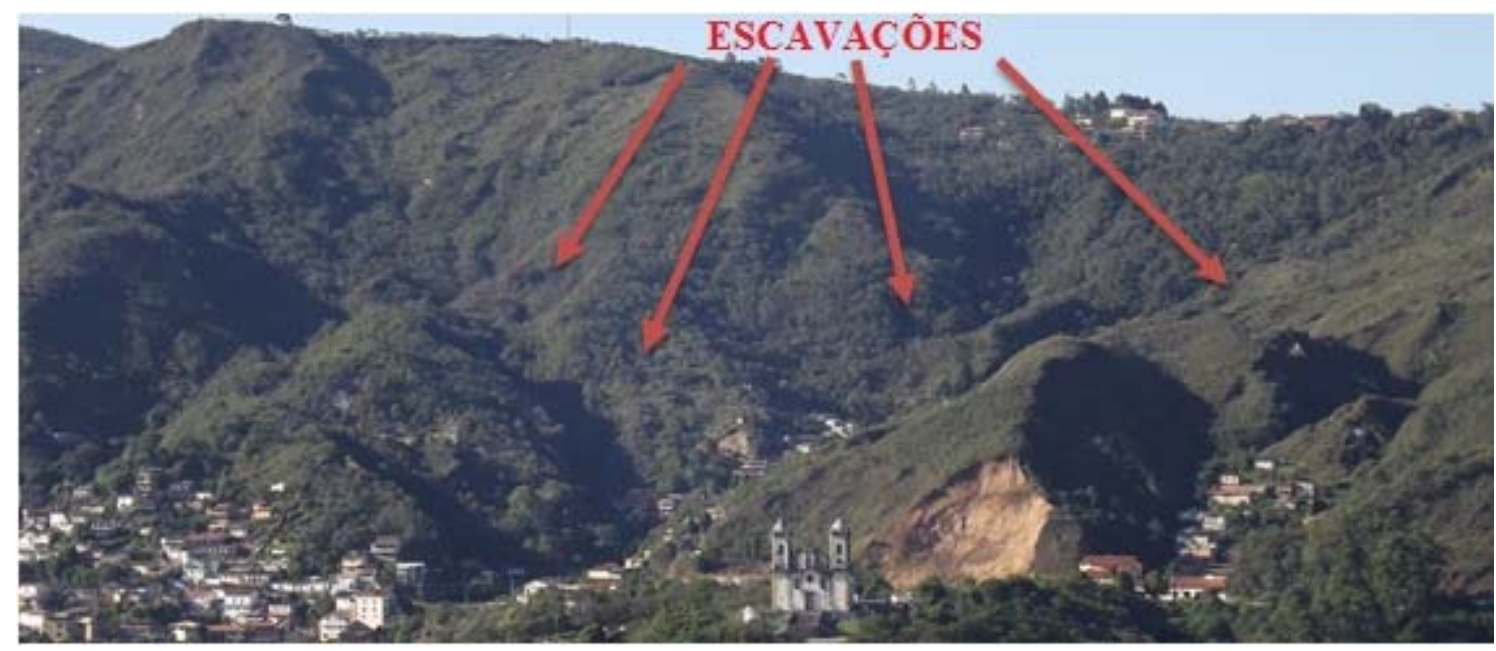

Figura 5: Vale escavado pelas atividades de mineração do século XVIII no local conhecido como Volta do Córrego

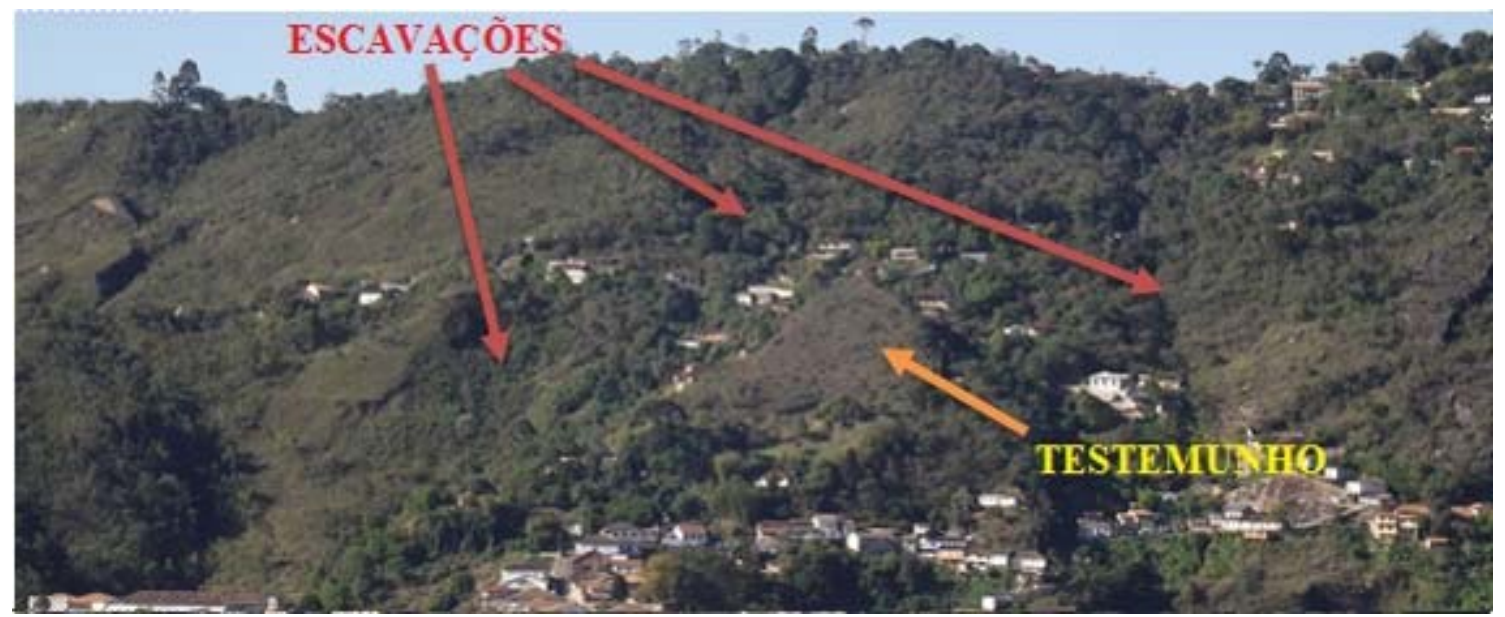

Figura 6: Vista geral do bairro Lajes, mostrando o relevo alterado e testemunhos da topografia original

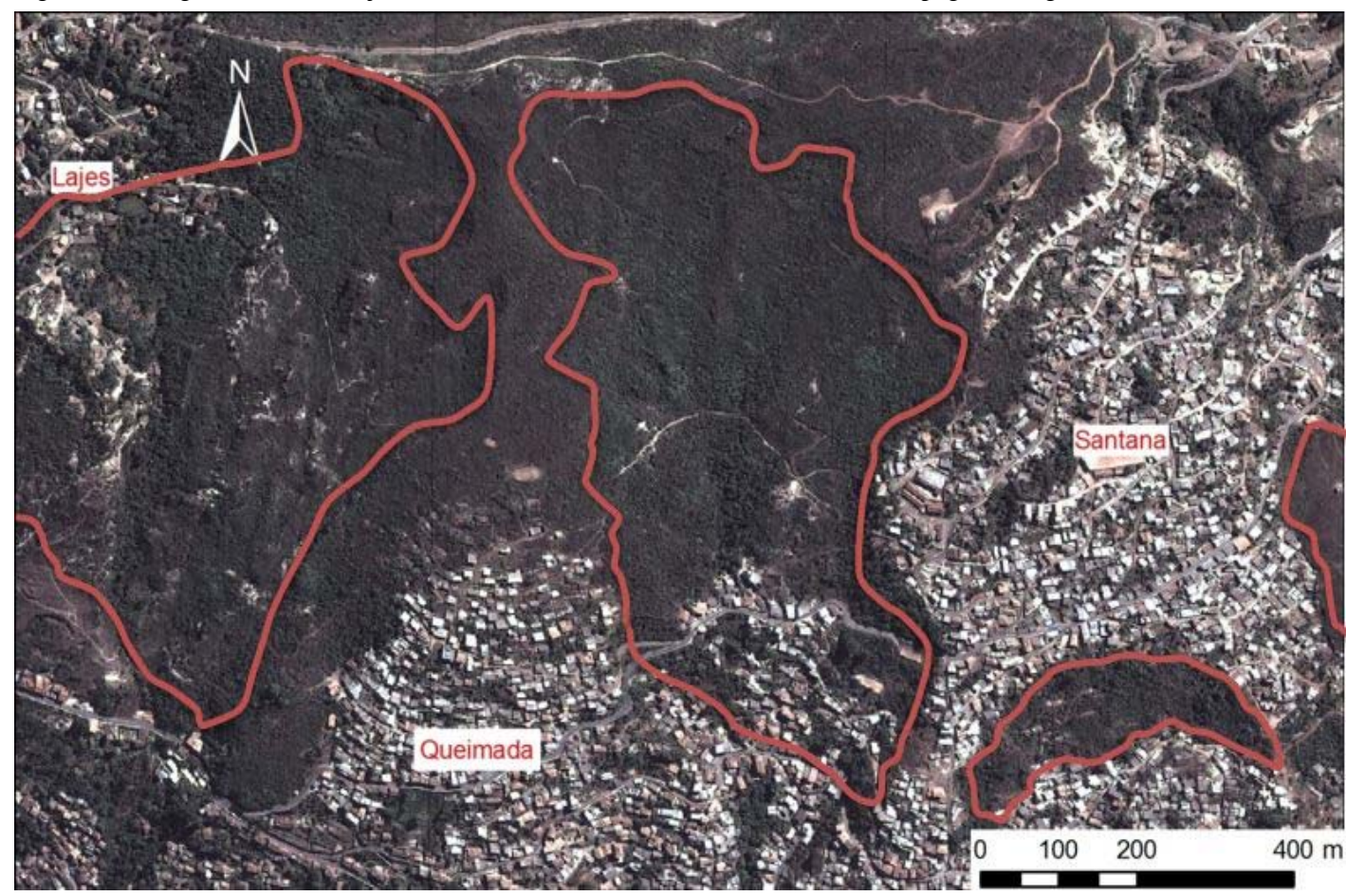

Figura 7: Vista aérea das escavações no entorno dos bairros Queimada, Santana e Lajes 


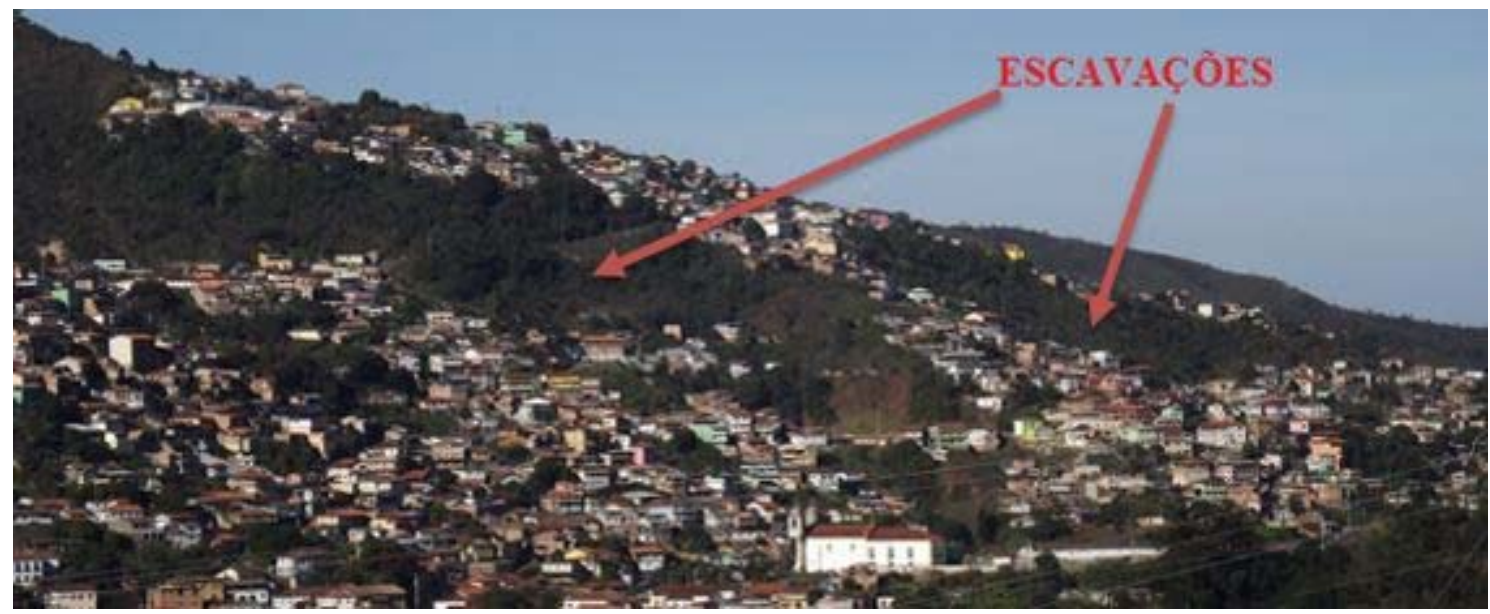

Figura 8: Alterações morfológicas nas vertentes nos bairros Piedade e Santana. A ocupação dá uma ideia do que foi alterado e os testemunhos da topografia original

No entanto, o local onde melhor se percebem os desmontes está a montante da área urbana do distrito de Passagem de Mariana (município de Mariana), na continuidade da serra de Ouro Preto a leste. Numa área de cerca de 200 hectares foram realizados grandes desmontes na encosta, desde o topo até a drenagem principal (ribeirão do Carmo), que resultaram na alteração total da morfologia local. Conforme Eschwege (1833), “as camadas que se estendem do Morro do Santo Antônio e constituem aqui o substratun geológico, foram completamente desnudadas, em consequência das lavagens das camadas sobrejacentes, em toda extensão que vai da margem do ribeirão até a lavra do Padre Bento”. O autor relata ainda que "sobre esses paredões ainda se observam, aqui e ali, como verdadeiras ilhas, restos da camada sobrejacente de itacolomito e de itabirito com crosta de tapanhocanga”. Paul Ferrand, em 1894, descreveu que "os trabalhos feitos no flanco da montanha devem ter sido muito importantes, a julgar pelo aspecto completamente remexido do terreno, e são uma prova evidente de que a jazida existia e era lucrativa”. As figuras 9 e 10 mostram aspectos desses terrenos escavados.

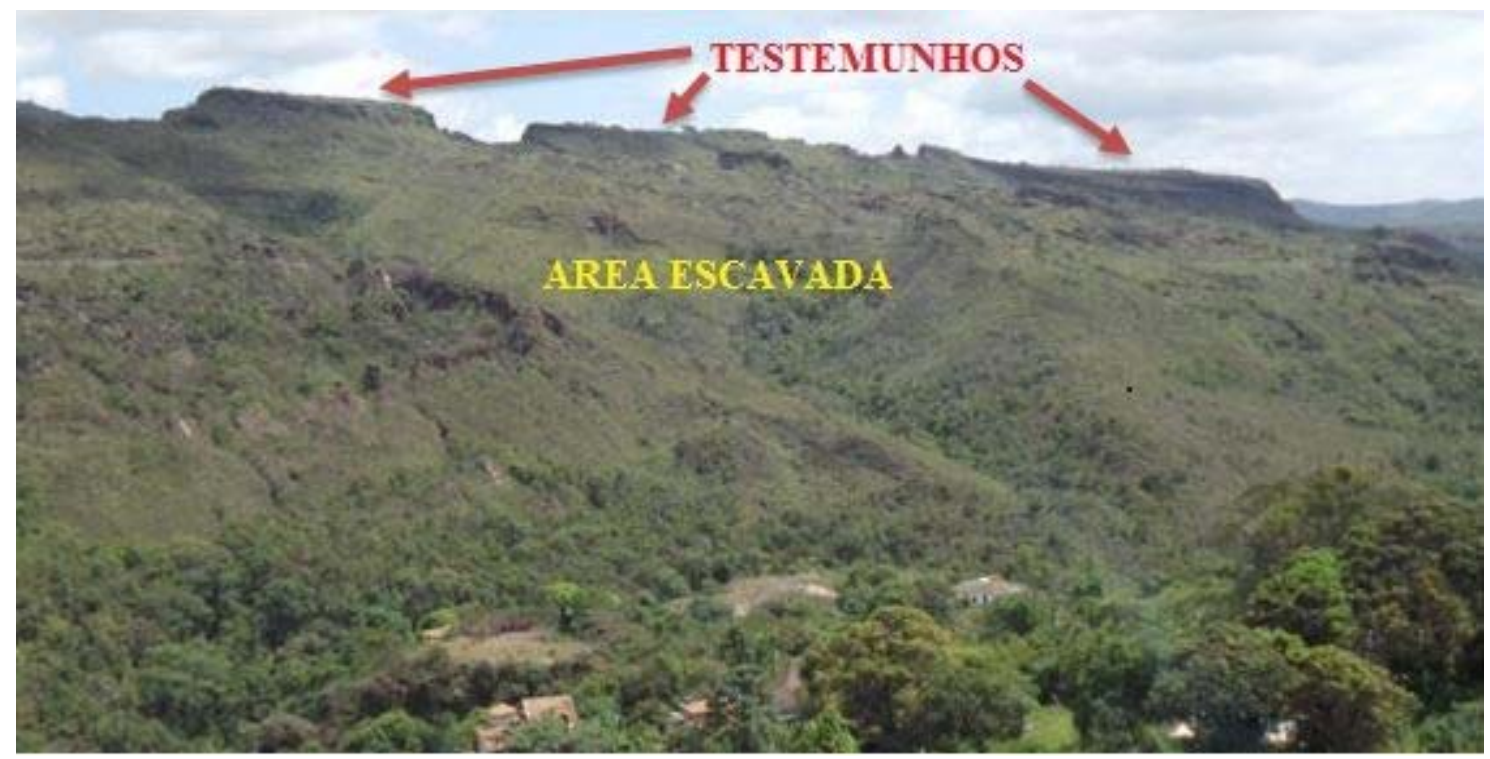

Figura 9: Vista geral da área a montante de Passagem de Mariana, com a topografia totalmente alterada pelas atividades de mineração do século XVIII 


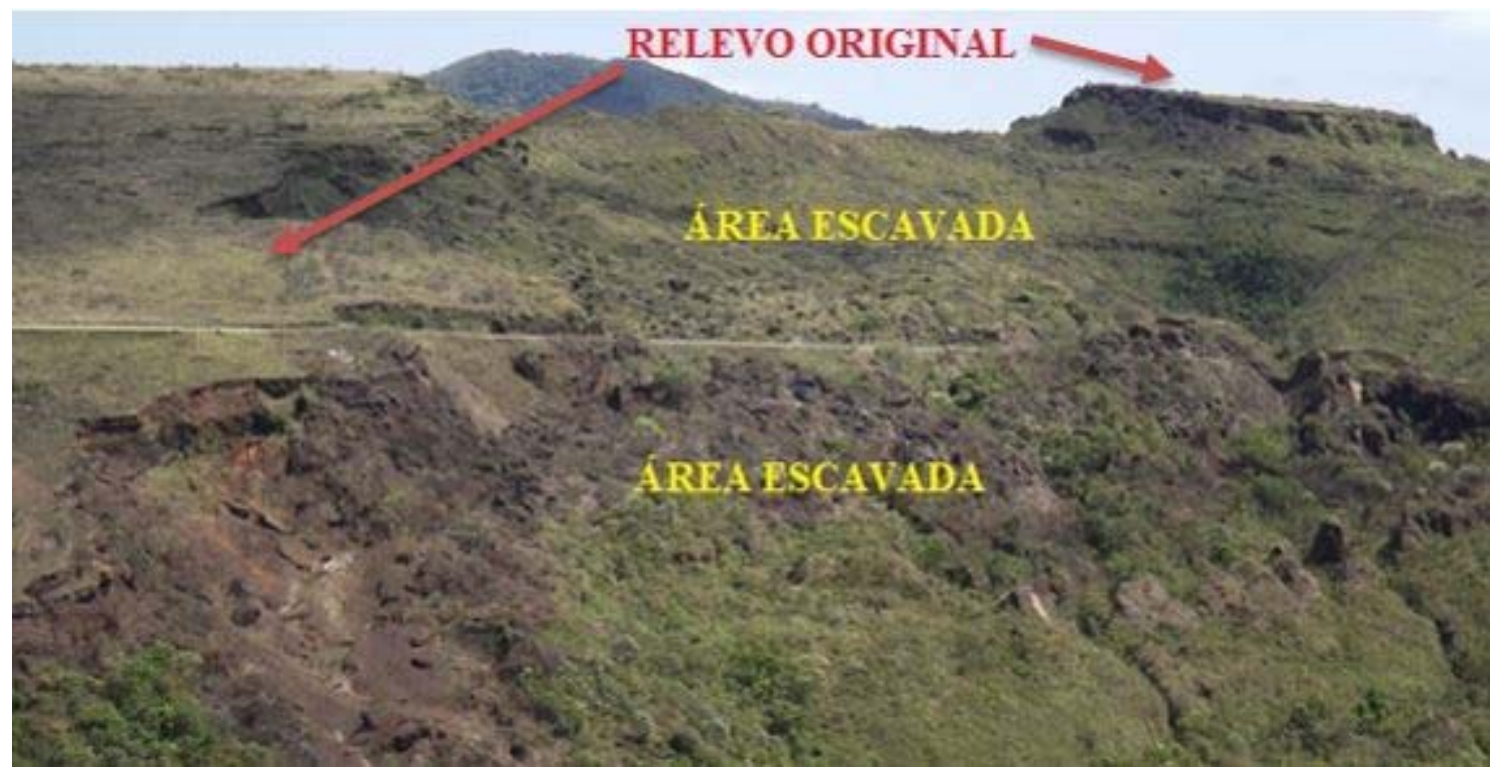

Figura 10: Detalhe das escavações em Passagem de Mariana

O sítio de Passagem de Mariana é o único local onde a ocupação urbana não avançou em direção às áreas escavadas. A preservação do sítio e a existência de vários testemunhos do relevo original dispersos na área possibilitaram a reconstituição aproximada da topografia original a partir de cartas topográficas em escala 1:5.000 (Sobreira et al. 2005). Esta reconstituição levou em conta os testemunhos existentes no interior da área afetada e o relevo das encostas circunvizinhas, não atingidas pelos trabalhos. O resultado foi uma aproximação do que seria a topografia original da região antes dos desmontes (figura 11). Pela diferença das formas atual e reconstituída foi possível então estimar-se o volume escavado pelas atividades mineiras. Para tal, aplicou-se o software Surpac Vision, gerando dois modelos de terreno (antes e depois dos desmontes) (figura 12) e calculou-se o volume de material escavado a partir da diferença entre as duas superfícies, chegando-se a um valor aproximado de 5,9 milhões de metros cúbicos.

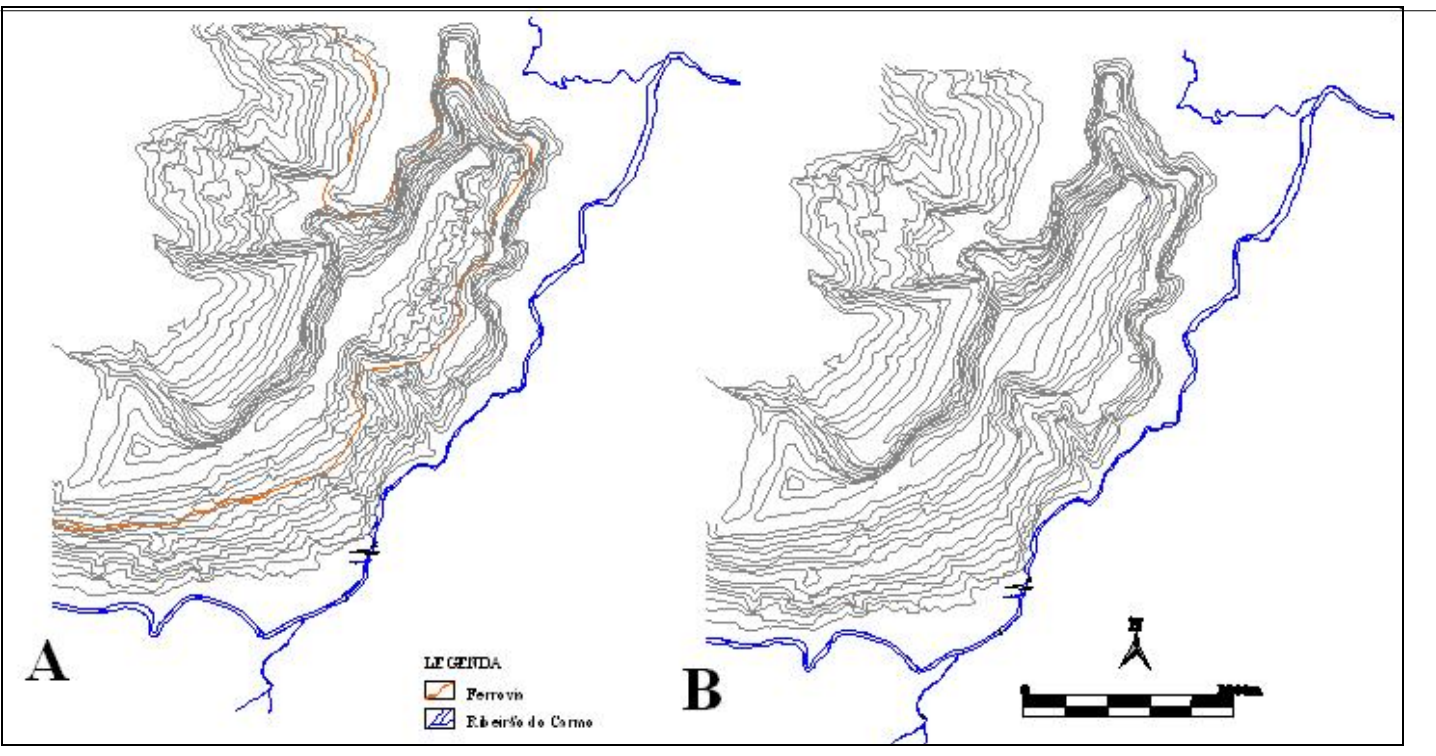

Figura 11: Representação da topografia atual (A) e reconstituída (B), base para a estimativa do volume de material extraído da encosta 


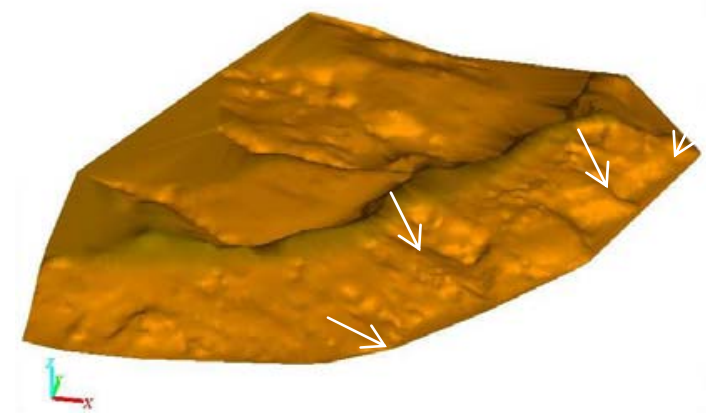

A

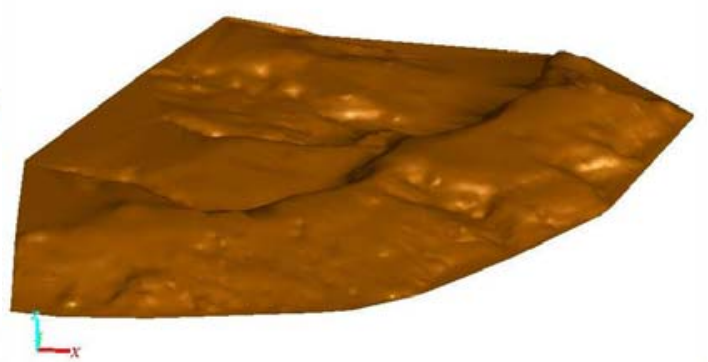

B

Figura 12: Representação das superfícies, atual (A) e reconstituída (B), gerada pelo software Surpac Vision, com destaque para as principais alterações

Como o material desmontado acabava sendo direcionado aos cursos de água após a separação do ouro, seu trajeto natural era o ribeirão do Carmo, que consequentemente sofreu grande assoreamento em seu leito para jusante, alcançando a região de Mariana, onde não houve atividades de desmontes consideráveis e as demais localidades a jusante, hoje distritos da cidade. Estes processos foram relatados por Eschwege (1833) na região de Mariana, onde parte do leito do ribeirão do Carmo foi elevado em mais de 20 metros.

Infelizmente, na década de 1980, a Companhia Minas de Passagem de Mariana, que detinha o alvará de exploração de grande área na região, efetuou a dragagem do material considerado estéril da Mina de Passagem de Mariana e acumulado no leito do ribeirão do Carmo (Tavares 2006). Estas atividades deram um resultado tão promissor que a companhia resolveu efetuar a dragagem do leito do ribeirão por todo o curso a jusante de Mariana, principalmente nas pequenas planícies aluvionares existentes. Esta intervenção pela busca do ouro remanejou todos os depósitos aluvionares, de forma que os registros e depósitos correlatos aos grandes desmontes de Ouro Preto e Passagem de Mariana foram destruídos, impossibilitando interpretações e correlações estratigráficas.

Foram feitas duas campanhas de campo pelo curso do ribeirão e seus afluentes no sentido de encontrar algum depósito preservado, mas a prática da dragagem foi tão predatória que nem mesmo as pequenas planícies de tributários do ribeirão permaneceram intactas. Os registros de sondagens na planície aluvionar de Monsenhor Horta (distrito de Mariana) mostraram um depósito totalmente remobilizado de correlação impossível, mesmo em pontos muito próximos. A esses fatos, soma-se o estado de degradação por poluição urbana do curso do ribeirão do Carmo, que impõe condições insalubres para o desenvolvimento de atividades, a abertura de poços e trincheiras, a coleta de material e as demais práticas de descrição de perfis dos depósitos.

\section{Conclusões}

As intensas atividades de mineração desenvolvidas principalmente no século XVIII deixaram vestígios remanescentes até os dias atuais, que constituem um importante acervo patrimonial geomineiro, permitindo a reconstituição dos trabalhos de mineração da época. Entre os diversos procedimentos adotados nos trabalhos mineiros destaca-se a mineração a céu aberto pelo desmonte manual ou hidráulico das vertentes, de forma a gerar uma lama, de onde o ouro era separado posteriormente. Estas atividades atingiram uma área de cerca de 300 hectares das vertentes da serra de Ouro Preto, principalmente a montante das áreas urbanas atuais de Ouro Preto e do distrito Passagem de Mariana.

Embora atualmente as atividades de mineração e de obras civis atinjam proporções muito maiores, as tecnologias empregadas na época e o trabalho lento e contínuo de dezenas de milhares de escravos por cerca de cem anos, promoveram uma alteração significativa na paisagem natural da serra, que pode ser caracterizada como um notável processo erosivo tecnogênico.

A delimitação e caracterização destas áreas mostraram que a ocupação urbana desordenada avança rapidamente em sua direção, configurando situações de risco geológico, uma vez que os terrenos trabalhados tiveram suas características naturais todas alteradas, e os depósitos e escavações remanescentes têm estabilidade precária e comportamento geotécnico desfavorável.

Os depósitos correlatos destas escavações, cujo material era lançado no curso do ribeirão do Carmo foram destruídos por atividades de dragagem do leito do rio em grande extensão a jusante de Passagem de Mariana por companhia de mineração na década de 1980, impedindo o avanço dos estudos. Assim, os depósitos tecnogênicos derivados da extração do ouro no século XVIII foram dizimados pela própria busca do ouro no século XX.

De qualquer forma, a paisagem modificada tem importância histórica e cultural para as cidades e região e deve ser integrada ao seu patrimônio geomineiro 
como testemunho da capacidade de alteração do meio físico pela ação antrópica, mesmo com técnicas primitivas.

\section{Agradecimentos}

O autor agradece ao CNPq e FAPEMIG pelo apoio financeiro ao estudo.

\section{Referências}

Calógeras J.P. 1904. As minas do Brasil e sua legislação. Companhia Editora Nacional, Rio de Janeiro, 508p.

Cavalcanti J.A. 1999. Mineração aurífera de Lages-Antonio Dias, Ouro Preto, MG: controles lito-estratigráficos e estruturais. 108p. Dissertação de Mestrado, Instituto de Geociências, Unicamp, 108p.

Door II J.V.N. 1969. Physiographic, Stratigraphic and Structural Development of the Quadrilátero Ferrífero, Minas Gerais, Brazil. United States Geological Survey, Professional Paper 641-A, 110p.

Eschwege W.L. 1833. Pluto Brasiliensis. Re-edição 1944, Cia Editora Nacional, São Paulo, 2v.

Ferrand P. 1894. L'or a Minas Geraes. Imprensa Official do Estado de Minas Geraes, Belo Horizonte, v. II, p.22-39.

Lacourt F. 1937. Jazidas auríferas de Ouro Preto e Mariana. Mineração e Metalurgia, Jul-A:87-95.

Lima H.M., Miranda J.F. 1996. Os 300 Anos da Atividade Garimpeira na Região de Ouro Preto e Mariana, Minas Gerais. Revista da Escola de Engenharia da UFRGS, Porto Alegre, 17:12-18.

Sobreira F.G. 1991. Riscos Geológicos: definição de pontos críticos em Ouro Preto. Revista da Escola de Minas, 44:213-223.

Sobreira F.G., Fonseca M.A. 2001. Impactos físicos e sociais de antigas actividades de mineração em Ouro Preto, Brasil. Geotecnia, 92:5-28.

Sobreira F.G., Lima H.M., Domingues A.L., Vicentim F.V. 2005. Alterações paisagísticas pela extração do ouro do século XVIII no distrito de Passagem de Mariana (município de Mariana, MG). In: I Simpósio brasileiro sobre o Tecnógeno, 2005, Guarapari. Anais do X Congresso da Associação brasileira de estudos do Quaternário. São Paulo: ABEQUA, CD-ROM.

Tavares R.B. 2006. Atividades extrativas minerais na bacia do Alto Ribeirão do Carmo: da descoberta do ouro aos dias atuais. 2006. Dissertação de Mestrado, Universidade Federal de Ouro Preto, 103p.

Vial D.S., Duarte B.P., Fuzikawa K., Vieira M.B.H. 2007. An epigenetic origin for the Passagem de Mariana gold deposit, Quadrilátero Ferrífero, Minas Gerais, Brazil. Ore Geology Reviews, 32:596-613 